\title{
The Calculation of Hydrodynamic Coefficients for Underwater Vehicles Using CFD Simulation
}

\author{
Le Quang $^{*}$, Pham.T.T.Huong ${ }^{1}$, Gregoire Galisson ${ }^{2}$ \\ ${ }^{1}$ Hanoi University of Science and Technology, Hanoi, Vietnam \\ ${ }^{2}$ Polytech Orlean, Region Centre Val de Loire, France \\ Email: quang.le@hust.edu.vn
}

\begin{abstract}
The manned diving underwater vehicles (UVs) are emerging as a significantcapability enhancer for future generation submarines. During the underwater scheme design period, the calculation of resistance is an important task. In practice, the motions of the vehicles can be decoupled into horizontal and vertical motion. Therefore, estimation of the hydrodynamic coefficients of movement back and forth (horizontal), movement down and up (vertical) is the key step to predict the motion of the underwater vehicles. Reynolds Averaged Navier-Stokes (RANS) simulations are carried out to numerically simulate the motion cases. This paper provides a detailed evaluation of the influence of seabed and water surface. The computational results are verified by comparison with the real data.It shows that method can be used to estimate the resistance of an underwater vehicle.
\end{abstract}

Keywords: Resistance, underwater vehicles, simulation, hydrodynamic coefficients

\section{Introduction}

Prediction of submarine resistance is an important task. It is also necessary to predict accurately the resistance of a submarine to design the propulsor. The resistance of submarine can be determined either by model testing (Planar Motion Mechanism-PMM) [1], or by Computational Fluid Dynamics (CFD), or by the potential theory.

The potential theory could predict the inertial hydrodynamic coefficients satisfactorily, but with the viscous terms neglected [2]. The PMM experiment may be the most effective way, but it requires special facilities and equipment and it is both timeconsuming and costly [3]. It is generally tested as deep as possible to avoid free surface effects. However, it is also necessary to avoid any influence from the bottom of the tank. So the PMM is not economical at the preliminary design stage. The method for determining the hydrodynamic derivatives is to use the Reynolds Averaged Navier-Stokes (RANS)[6] simulations to simulate the movement of a real underwater vehicle. It is possible to achieve the full-scale Renolds number. The steadystate CFD was successfully applied to simulate the straight line [1,3]. Reynolds-Averaged Navier-Stokes (RANS) equations are the oldest approach to turbulence modeling. The paper shows the results from $k-\varepsilon ; k-\omega$ and Spalart-allmaras model. The computational results are verified by comparison with the reality data and show thatthe model can be used.

ISSN: 2734-9373

https://doi.org/10.51316/jst.150.ssad.2021.31.1.12 Received: 23 April 2020; accepted: 18 August 2020
We calculated for movement back and forth (horizontal), movement down and up (vertical), and evaluated the influence of seabed and water surface by calculating the resistant coefficients of vehicle's motion near a seabed or a free surface. The motion near water surface effects on the hydrodynamic coefficients investigated by using the finite volume method (VOF) available in software Ansys Fluent.

Thisstudy aims to explore the possibility of developing turbulent models and the numerical method to evaluate the motion characteristics of underwater vehicles at all stages.

\section{Numerical Approach}

\subsection{Governing Equations}

Numerical simulations are performed with the CFD software Ansys Fluent. The flow around the vehicle is modeled using the incompressible, RANS equations [2]:

$$
\begin{aligned}
& \frac{\partial\left(u_{i}\right)}{\partial x_{i}}=0 \\
& \frac{\partial\left(\rho u_{i}\right)}{\partial t}+\rho u_{j} \frac{\partial u_{i}}{\partial x_{j}}=\rho F_{i}-\frac{\partial P}{\partial x_{i}} \\
& \frac{\partial}{\partial x_{j}}\left(\mu \frac{\partial u_{i}}{\partial x_{j}}-\rho \overline{u_{i}^{\prime} u_{j}^{\prime}}\right)
\end{aligned}
$$

where $u_{i}$ is the time averaged velocity components in Cartesian coordinates $x_{i}(i=1,2,3), \rho$ is the fluid density, $F_{i}$ is the body forces, Pis the time averaged pressure, $\mu$ is the viscous coefficient, $u_{i}^{\prime}$ is the 
fluctuating velocitycomponents in Cartesian coordinates, and $-\rho \overline{\mathrm{u}_{i}^{\prime} \mathrm{u}_{j}^{\prime}}$ is the Reynolds stress tensor.In order to allow the closure of the time averaged Navier-Stokes equations, various turbulence models were introduced to provide an estimation of the $-\rho \overline{\mathrm{u}_{i}^{\prime} \mathrm{u}_{j}^{\prime}}, k-\varepsilon$ is best suited for flow away from the wall, say free flow region, whereas $k-\omega$ model flow is best suited for near the wall flow region, where adverse pressure gradient is developed. Models $k-\omega$ and $k-\varepsilon$ are two equation models. These are semi-analytic models. On the other way SpalartAllmaras model is one-equation model, which isdeveloped and used extensively for aerospace industry application [6]. Here all models are applied for a better analysis of the turbulent viscous flow around the underwater vehicle in infinite fluid.

\subsection{Description of the Model}

\subsubsection{Model $k-\varepsilon$}

The transport equations can be written for standard $k-\varepsilon$ model [2] as follows:

- For turbulent kinetic energy $k$

$$
\begin{gathered}
\frac{\partial}{\partial t}(\rho k)+\frac{\partial}{\partial x_{i}}\left(\rho k u_{i}\right)=\frac{\partial}{\partial x_{j}}\left[\left(\mu+\frac{\mu_{t}}{\mu_{k}}\right) \frac{\partial k}{\partial x_{j}}\right]+ \\
+P_{k}+P_{b}-\rho \varepsilon-Y_{M}+S_{k}
\end{gathered}
$$

- For dissipation $\varepsilon$

$$
\begin{array}{r}
\frac{\partial}{\partial_{t}}(\rho \varepsilon)+\frac{\partial}{\partial x_{i}}\left(\rho \varepsilon u_{i}\right)=\frac{\partial}{\partial x_{j}}\left[\left(\mu+\frac{\mu_{t}}{\mu_{\varepsilon}}\right) \frac{\partial \varepsilon}{\partial \mathrm{x}_{j}}\right]+ \\
+C_{1 \varepsilon} \frac{\varepsilon}{k}\left(P_{k}+C_{3 \varepsilon} P_{k}\right)-C_{2 \varepsilon} \rho \frac{\varepsilon^{2}}{k}+S_{\varepsilon}
\end{array}
$$

Turbulent viscosity is modeled as:

$$
\mu_{t}=\rho C_{\mu} \frac{k^{2}}{\varepsilon}
$$

Production of $k$

$$
\begin{aligned}
& P_{k}=-\rho \overline{u_{i}^{\prime} u_{j}^{\prime}} \frac{\partial \mathrm{u}_{j}}{\partial \mathrm{x}_{i}} \\
& \mathrm{P}_{2}=\mu_{t} \mathrm{~S}^{2}
\end{aligned}
$$

where $\mathrm{S}$ is the modulus of the mean rate-of-strain tensor, defined as:

$$
S \equiv \sqrt{2 S_{i j} S_{j i}}
$$

Effect of buoyancy

$$
P_{b}=\rho g_{i} \frac{\mu_{t}}{P r_{t}} \cdot \frac{\partial T}{\partial x_{i}}
$$

where $P r_{t}$ is the turbulentPrandtl number for energy and $g_{i}$, which is the component of the gravitational vector in the ith direction. For the standard and realizable - models, the default value of $P r_{t}$ is 0.85 .

The coefficient of thermal expansion, $\beta$, is defined as

$$
\beta=-\frac{1}{\rho}\left(\frac{\partial \rho}{\partial T}\right)_{p}
$$

Model constants

$$
\begin{aligned}
& C_{1 \varepsilon}=1.44 ; C_{2 \varepsilon}=1.92 ; C_{\mu}=0.09 ; \\
& \sigma_{k}=1.0 ; \sigma_{\varepsilon}=1.3
\end{aligned}
$$

2.2.2 Kinematic Eddy Viscosity $k-\omega$ [2]

$$
v_{T}=\frac{k}{\omega}
$$

- Turbulence Kinetic Energy

$$
\begin{aligned}
\frac{\partial k}{\partial t}+U_{j} \frac{\partial k}{\partial x_{j}}= & \tau_{i j} \frac{\partial U_{i}}{\partial x_{j}}-\beta^{*} k \omega \\
& +\frac{\partial}{\partial x_{j}}\left[\left(v+\sigma^{*} v_{T}\right) \frac{\partial k}{\partial x_{j}}\right]
\end{aligned}
$$

- Specific Dissipation Rate

$$
\begin{aligned}
\frac{\partial \omega}{\partial t}+U_{j} \frac{\partial \omega}{\partial x_{j}} & =\alpha \frac{\omega}{k} \tau_{i j} \frac{\partial U_{i}}{\partial x_{j}}-\beta \omega^{2} \\
& +\frac{\partial}{\partial x_{j}}\left[\left(v+\sigma v_{T}\right) \frac{\partial \omega}{\partial x_{j}}\right]
\end{aligned}
$$

Closure coefficients and Auxilary relations:

$$
\begin{aligned}
& \alpha=\frac{5}{9} ; \beta=\frac{3}{40} ; \beta^{*}=\frac{9}{100} \\
& \sigma=\frac{1}{2} ; \sigma^{*}=\frac{1}{2} ; \varepsilon=\beta^{*} \omega k
\end{aligned}
$$

\subsubsection{Spalart-Allmaras model [2]}

Spalart-Allmarasmodel is a one equation model which solves a transport equation for a viscosity-like variable $\tilde{v}$. This may be referred to as the SpalartAllmarasvariable.

Original model

- The turbulent eddy viscosity is given by

$$
v_{t}=\tilde{v} f_{v 1} ; f_{v 1}=\frac{\chi^{3}}{\chi^{3}+C_{v 1}^{3}} ; \chi=\frac{\tilde{v}}{v}
$$

$\frac{\partial \tilde{v}}{\partial t}+\mathrm{u}_{j} \frac{\partial \tilde{v}}{\partial \mathrm{x}_{j}}=C_{b 1}\left[1-f_{t 2}\right] \tilde{S} \tilde{v}+$

$$
\begin{aligned}
& +\frac{1}{\sigma}\left\{\nabla[(v+\tilde{v}) \nabla \tilde{v}]+C_{b 2}|\nabla \tilde{v}|^{2}\right\}- \\
& -\left[C_{\omega 1} f_{\omega}-\frac{C_{b 1}}{k^{2}} f_{t 2}\right]\left(\frac{\tilde{v}}{d}\right)^{2}+f_{\mathrm{t} 1} \Delta U^{2}
\end{aligned}
$$




$$
\tilde{S} \equiv S+\frac{\tilde{v}}{k^{2} d^{2}} f_{v 2} ; f_{v 2}=1-\frac{\chi}{1+\chi f_{v 1}}
$$

where:

$$
\begin{aligned}
& S \equiv \sqrt{2 \Omega_{i j} \Omega_{j i}} \\
& \Omega_{i j} \equiv \frac{1}{2}\left(\frac{\partial \mathrm{u}_{i}}{\partial \mathrm{x}_{j}}-\frac{\partial \mathrm{u}_{j}}{\partial \mathrm{x}_{i}}\right) \\
& f_{\omega}=g\left[\frac{1+C_{\omega 3}^{6}}{g^{6}+C_{\omega 3}^{6}}\right]^{1 / 6} \\
& g=r+C_{\omega 2}\left(r^{6}-r\right) ; r \equiv \frac{\tilde{v}}{\tilde{S} k^{2} d^{2}} \\
& f_{t 1}=C_{t 1} g_{t} \exp \left\{-C_{t 2} \frac{\omega_{t}^{2}}{\Delta U^{2}}\left(d^{2}+g_{t}^{2} \mathrm{~d}_{t}^{2}\right)\right\} \\
& f_{t 2}=C_{t 3} \exp \left\{-C_{t 4} \chi^{2}\right\}
\end{aligned}
$$

dis the distance to the closest surface. These constants are:

$$
\begin{aligned}
& \sigma=\frac{2}{3} ; C_{b 1}=0.1355 ; C_{b 2}=0.622 ; k=0.41 \\
& C_{\omega 1}=\frac{C_{b 1}}{k^{2}}+\frac{1+C_{b 2}}{\sigma} ; C_{\omega 2}=0.3 ; C_{\omega 3}=2 \\
& C_{v 1}=7.1 ; C_{t 1}=1 ; C_{t 2}=2 ; C_{t 3}=1.1 ; C_{t 4}=2
\end{aligned}
$$

In order to calculate ship resistance, an underwater vehicle [4,5] with principal technical parameters as shown in table 1 is selected.

Table 1. Principle technical parameters of the vehicle

\begin{tabular}{|l|c|r|}
\hline \multicolumn{1}{|c|}{ Content } & $\begin{array}{c}\text { Symbol } \\
\text { (Unit) }\end{array}$ & \multicolumn{1}{c|}{ Value } \\
\hline Length & $L(m)$ & 4.074 \\
\hline Height & $H(m)$ & 2.358 \\
\hline Breadth & $B(m)$ & 2.430 \\
\hline $\begin{array}{l}\text { Draught without water in } \\
\text { the } 4 \text { floats }\end{array}$ & $T(m)$ & 1.490 \\
\hline Weight & $D(N)$ & 68566.7 \\
\hline Sea water density & $\rho\left(\mathrm{kg} / \mathrm{m}^{3}\right)$ & 1035 \\
\hline Velocity in infinite Fluid & $V(\mathrm{Hl} / \mathrm{h})$ & \\
\hline $\begin{array}{l}\text { Forward with trust }= \\
4513 \mathrm{~N}\end{array}$ & $V_{F}$ & $4.0 \div 4.5$ \\
\hline $\begin{array}{l}\text { Back with thrust }= \\
2590 \mathrm{~N}\end{array}$ & $V_{b}$ & $2.0 \div 2.5$ \\
\hline $\begin{array}{l}\text { Movement down trust }= \\
826 \mathrm{~N}\end{array}$ & $V_{d}$ & $1.1 \quad 1.3$ \\
\hline Movement up trust $=501 \mathrm{~N}$ & $V_{u}$ & $0.1 \quad 0.2$ \\
\hline
\end{tabular}

The numerical model has the same overall length and principal geometry as reality.

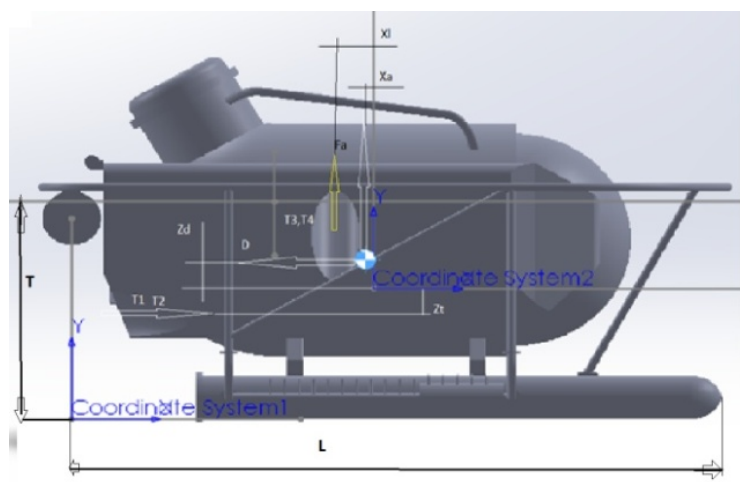

a) Side view

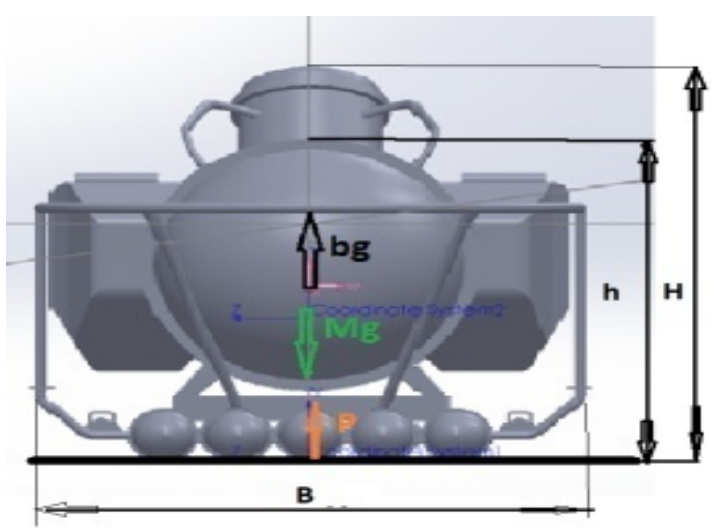

b) Front view

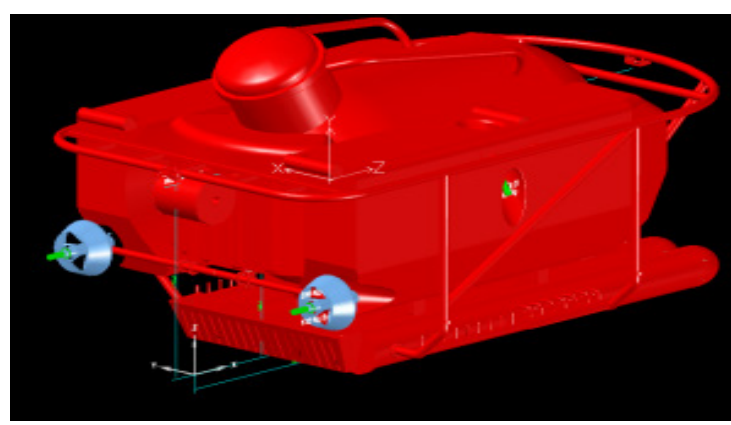

c) Projection $3 \mathrm{D}$

Fig. 1. Geometry of underwater vehicle

\subsection{Mesh Definition and Boundary Conditions}

In order to simulate the motion of the model, the fluid domain is split into 2 domains: an inner region, andan outner region. In the inner region, a multi-block mesh is used to define the fluid immediately surrounding the vehicle, which allows a detailed control of mesh parameters and elements quality. The skewness value is about 0.22 . The inlet boundary is positioned 3 body length upstream with velocity from $0.5 \mathrm{~m} / \mathrm{s}$ to $4 \mathrm{~m} / \mathrm{s}$ with a step of $0.5 \mathrm{~m} / \mathrm{s}$ (Reynolds number of $1,613.10^{7}$ based on the vehicle length of $4.074 \mathrm{~m}$ and velocity of $4 \mathrm{~m} / \mathrm{s}$ ). A pressure-outlet condition is defined 5 body-length downstream. Free 
slip wall boundary condition was applied to the 4 remaining walls 5 diameters away from the model and no-slip boundary condition was applied to the hull. Fig.2 shows the mesh distribution with 2.9 million elements.

For the method of calculating turbulence, three models are used: the model $k-\varepsilon$, this model is efficient and inexpensive, then the model $k-\omega$ is used, this model is a little more accurate but more expensive. And finally, the model Spalart Allmaras is applied.This model is less expensive than the other two because there is only one equation.It is adapted in this type of turbulence because the turbulence generated by the flow is low. Several models are simulated to check the correlation of the results. The simulation method of the motion on the water surface (floating)was different from the others.In fact, the submarine moving to the surface with the base at $1,487 \mathrm{~m}$ deep and the rest outside the water. The simulation requires the presence of two fluids as in Fig.3(sea water and air). For this simulation, the VOF (volume of fluid) calculation method is used, which simulates in several fluids.

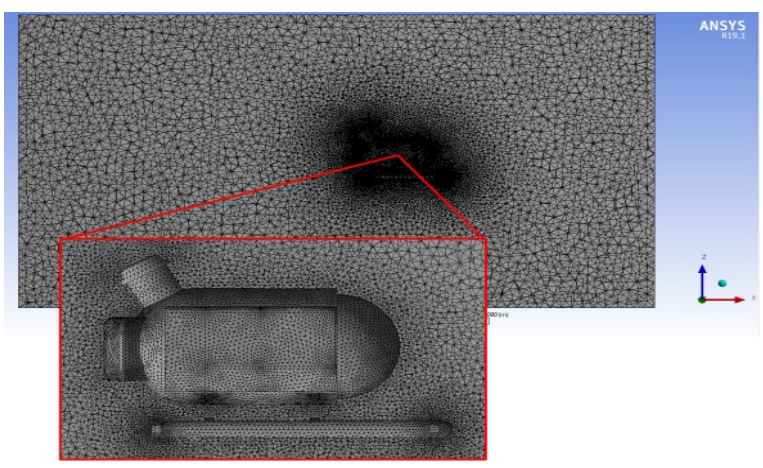

Fig. 2. Mesh with 2.9 million elements
The VOF method is known as one of the most effective numerical techniques handing two-fluid domains of different densities simultaneoustly. The present study deals with the numerical analysis of the flow field around the vehicle steadily moving near free-surface or on free-surface (floating) using the FLUENT-VOF method. The number of phases present in this case is 2 . Then the implicit formulation is used as well as open chanel flow. The two desired phases are then to be defined here, seawater and air.

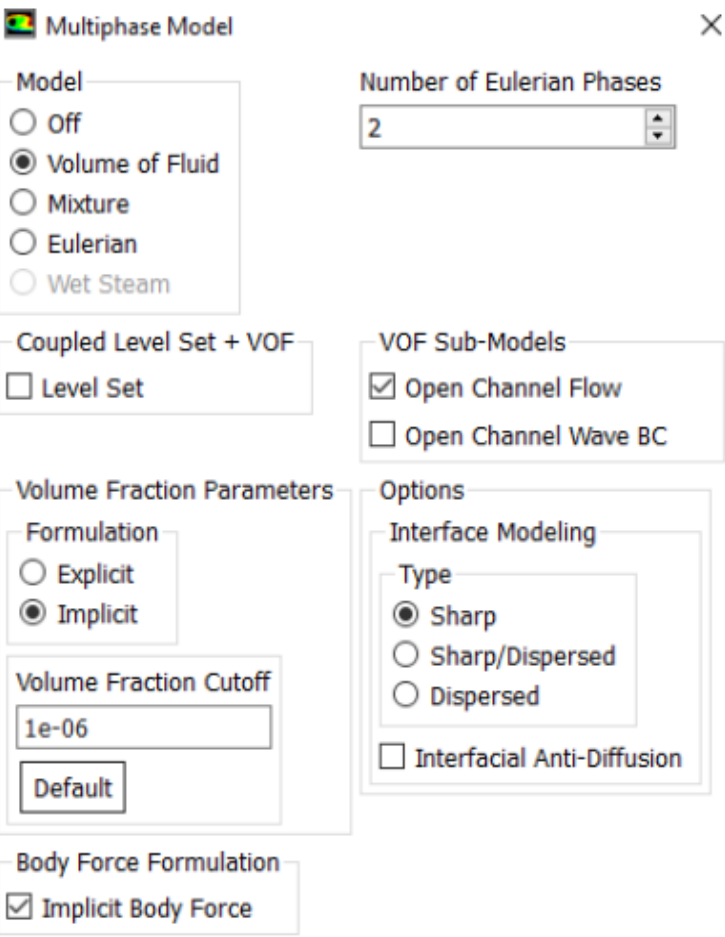

Fig. 3. Multiphase Model- VOF method

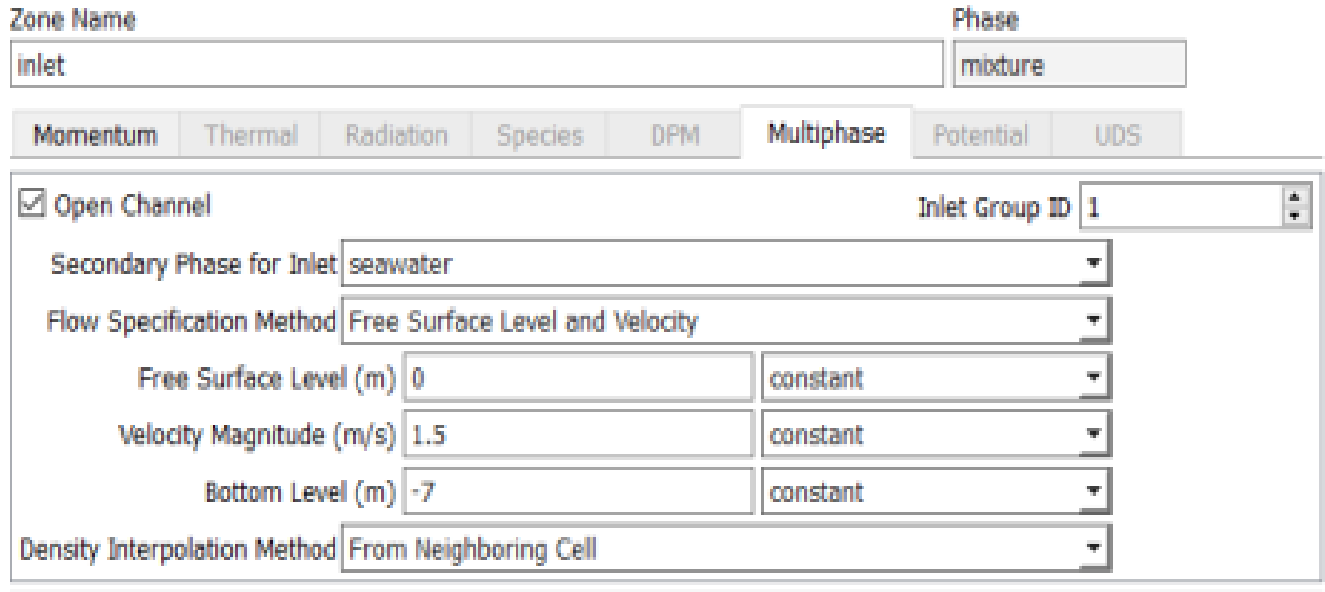

Fig. 4. Parameters of boundary conditions 
Before proceeding the CFD analysis, the sensibility of the solutions of the grid should be determined. Star from an initial grid selected by the skewness value, the quality of a mesh can be defined as in Table 2.

Table 2. Quality of mesh

\begin{tabular}{|l|c|}
\hline \multicolumn{1}{|c|}{ Quality } & Skewness value \\
\hline Excellent & $0 \div 0.25$ \\
\hline Good & $0.25 \div 0.50$ \\
\hline Acceptable & $0.50 \div 0.80$ \\
\hline Poor & $0.80 \div 0.95$ \\
\hline Very poor & $0.95 \div 0.99$ \\
\hline bad & $0.99 \div 1.00$ \\
\hline
\end{tabular}

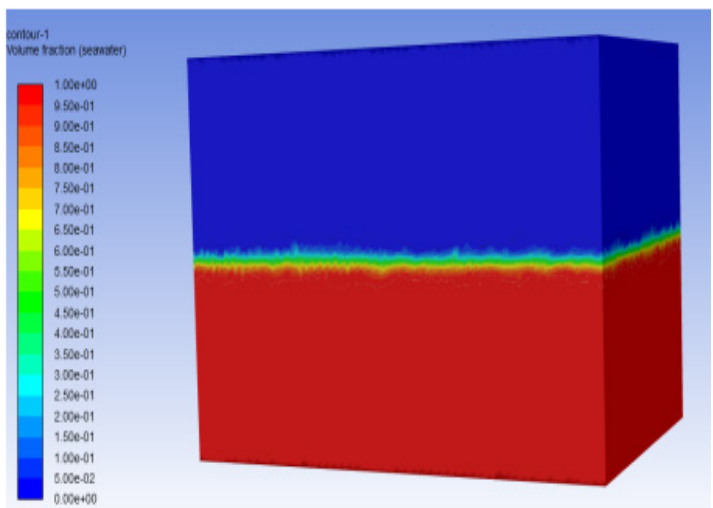

Fig. 5. Domain calclation for two - phase flow (seawater and air)

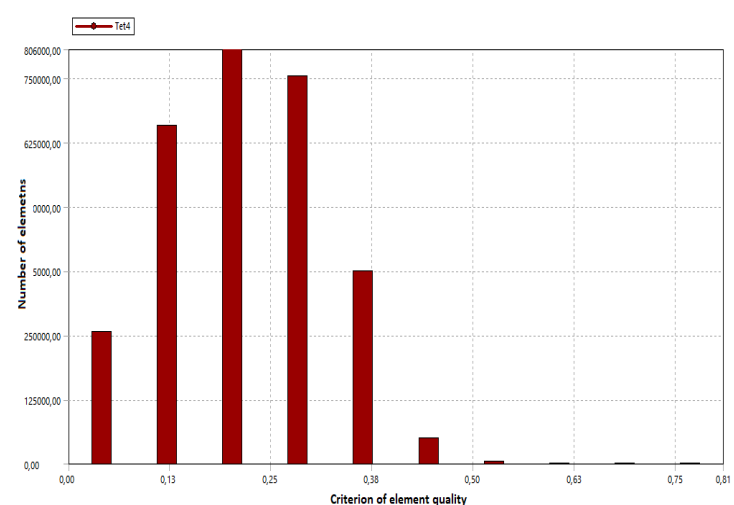

Fig. 6. Distribution of meshes according to quality

Once the mesh was achieved, the quality of the elements was evaluated with the skewness setting. On the domain near the wall or near the free surface the value of skewness is 0 , the better the quality, and on the domain away from the wall, the value of skewness is between 0 and 0.5 The average is 0.22 and the standard deviation is 0.1 , which means that $99.74 \%$ of the values have a skewness between 0 and 0.5. The mesh is therefore good, as seen in Fig.6.
The quality of the mesh plays a significant role in the accuracy and stability of the numerical computation. After comparing the results from the base grid and refined grids and with the limited computational the mesh parameters and number of elements were chosen.

\section{Results and Discussion}

Fig. 7 a,b show the pressure and the velocity distribution in motion forth in infinite fluid with velocity $V_{F}=2.5 \mathrm{~m} / \mathrm{s}$.

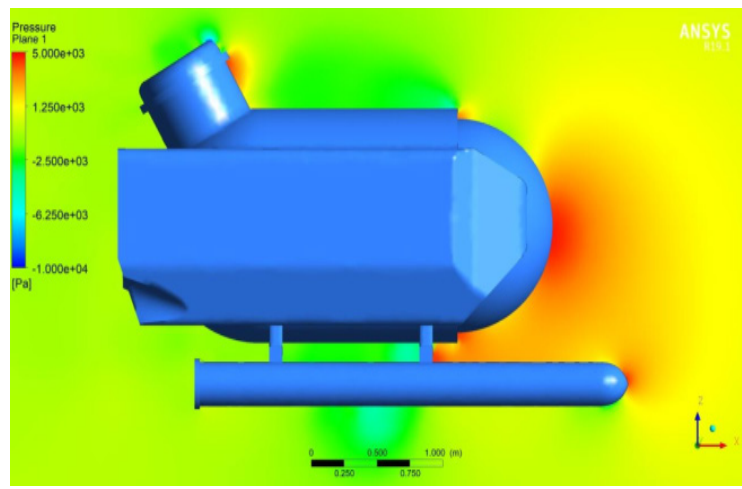

Fig. 7. a) Pressure distribution in motion forth in infinite fluid $\left(V_{F}=2.5 \mathrm{~m} / \mathrm{s}, C_{D}=0.382\right)$

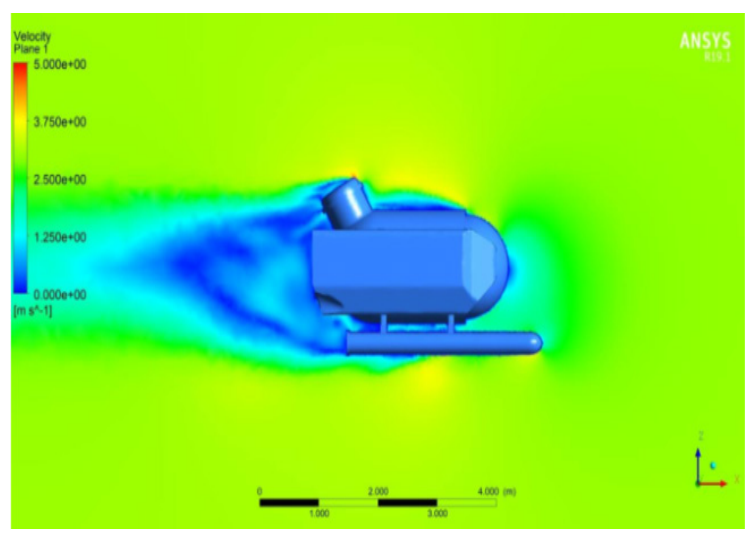

Fig. 7. b) Velocity distribution in motion forth in infinie fluid $\left(V_{F}=2.5 \mathrm{~m} / \mathrm{s}, C_{D}=0.382\right)$

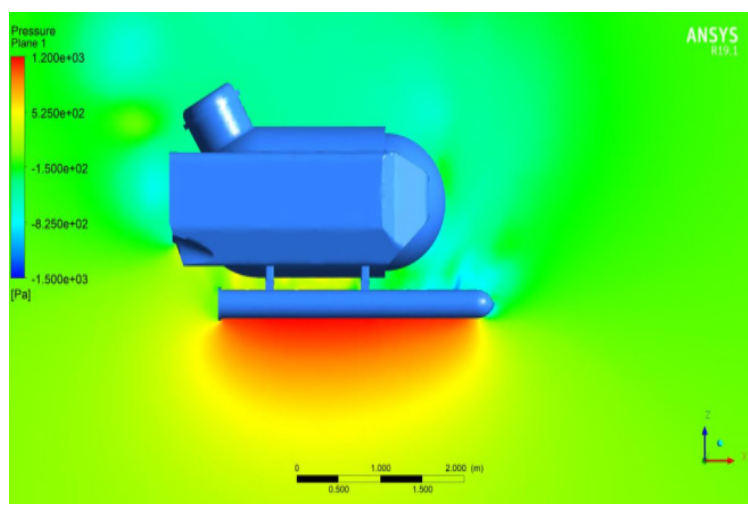

Fig. 8. a) Pressure distribution in motion down vertical $\left(V_{D}=1.5 \mathrm{~m} / \mathrm{s}, C_{D}=0.903\right)$ 


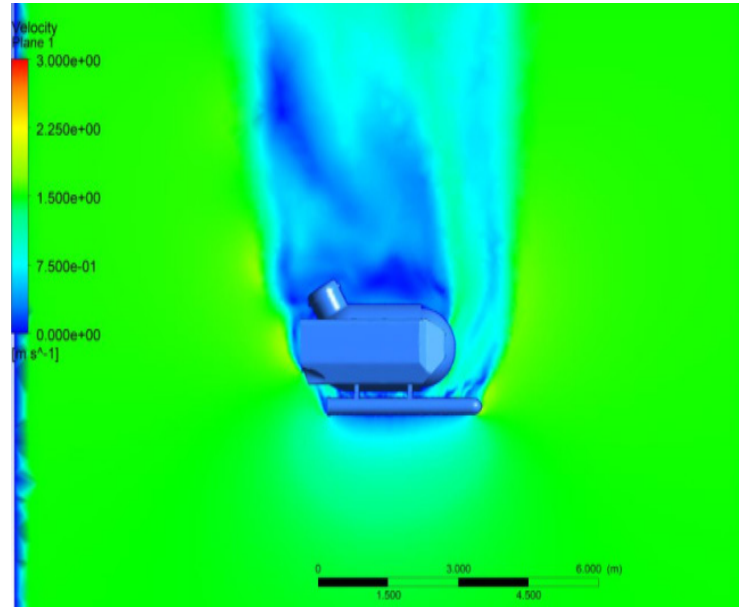

Fig. 8. b) Velocity distribution in motion down vertical $\left(V_{D}=1.5 \mathrm{~m} / \mathrm{s}, C_{D}=0.903\right)$

Fig. 8. a,b. show the distribution velocity and pressure around the vehicle in motion vertical down.

Resistance coefficient is defined as:

$$
C_{D}=\frac{2 F_{D}}{\rho S V^{2}}
$$

where, $F_{D}(N)$ - Force resistance; $\rho=1035 \mathrm{~kg} / \mathrm{m}^{3}$ density of sea water, $S=5.7 \mathrm{~m}^{2}$ - reference area (the largest cross-angle bracket with motion).

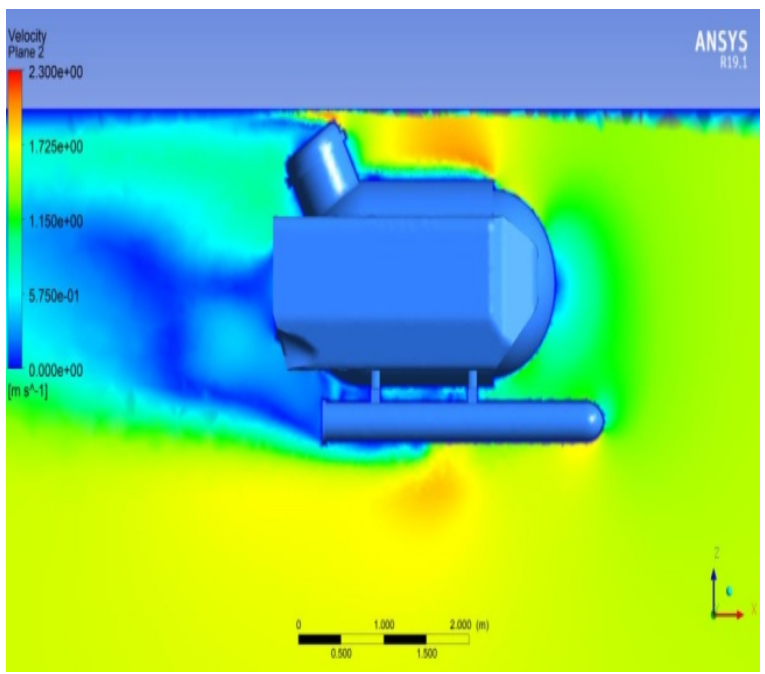

Fig. 9. Velocity distribution in motion near a water surface $0.1 \mathrm{~m}\left(V_{F}=1.5 \mathrm{~m} / \mathrm{s}, C_{D}=0.480\right)$.

We calculate the velocity from $0.5 \mathrm{~m} / \mathrm{s}$ to $3.0 \mathrm{~m} / \mathrm{s}$ when the vehicle advances in infinite fluid with three different turbulent models of $k-\varepsilon ; k-\omega$ and Spalart Allmaras. The difference of velocity results in case $V_{F}=3 \mathrm{~m} / \mathrm{s}$ between models is $(0.5-5.2) \%$. The difference between the $k-\varepsilon$ and Spalart Allmaras models is significant(about 7\%) when $V_{F}=2.5 \mathrm{~m} / \mathrm{s}$ (Table 5)
Table 3. Resistances and coefficients $C_{D}$ in motion near a water surface $0.1 \mathrm{~m}\left(V_{F}=1.5 \mathrm{~m} / \mathrm{s}\right)$.

\begin{tabular}{|l|l|l|l|l|}
\hline & \multicolumn{2}{|l|}{ Turbulence model } & $\begin{array}{l}\text { VOF } \\
-2 \text { fluid }\end{array}$ \\
\hline $\begin{array}{l}V_{F}= \\
1.5 \mathrm{~m} / \mathrm{s}\end{array}$ & $k-\varepsilon$ & $k-\omega$ & $\begin{array}{l}\text { Spalart- } \\
\text { Allmaras }\end{array}$ & $k-\varepsilon$ \\
\hline$F_{D}(N)$ & 3212 & 3241 & 3411.7 & 3371.7 \\
\hline$C_{D}$ & 0.498 & 0.488 & 0.506 & 0.476 \\
\hline
\end{tabular}

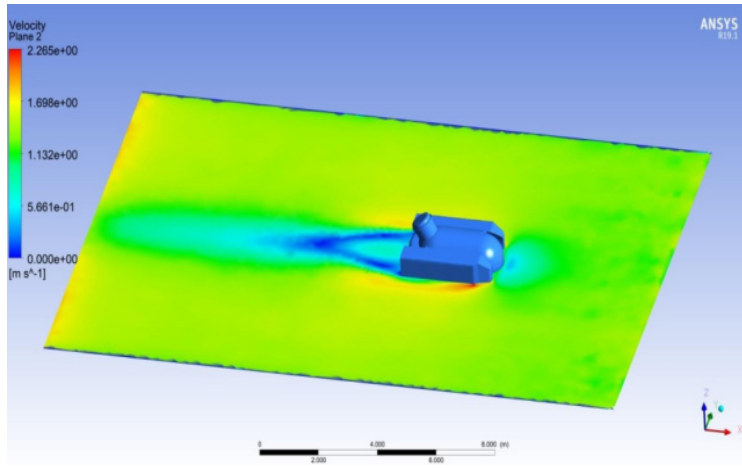

Fig. 10. Velocity distribution in motion on water surface (floating) $\left(V_{F}=2.5 \mathrm{~m} / \mathrm{s}, C_{D}=0.261\right)$

Table 4. Resistances and coefficients $C_{D}$ in motion on water surface $\left(V_{F}=1.5 \mathrm{~m} / \mathrm{s} ; V_{F}=2.5 \mathrm{~m} / \mathrm{s}\right)$

\begin{tabular}{|l|l|l|}
\hline $\begin{array}{c}\text { Model } \\
k-\varepsilon\end{array}$ & \multicolumn{2}{|l|}{ VOF - two Fluids } \\
\cline { 2 - 3 } & $1.5 \mathrm{~m} / \mathrm{s}$ & $2.5 \mathrm{~m} / \mathrm{s}$ \\
\hline$F_{D}(N)$ & 1760.1 & 4793.3 \\
\hline$C_{D}$ & 0.260 & 0.261 \\
\hline
\end{tabular}

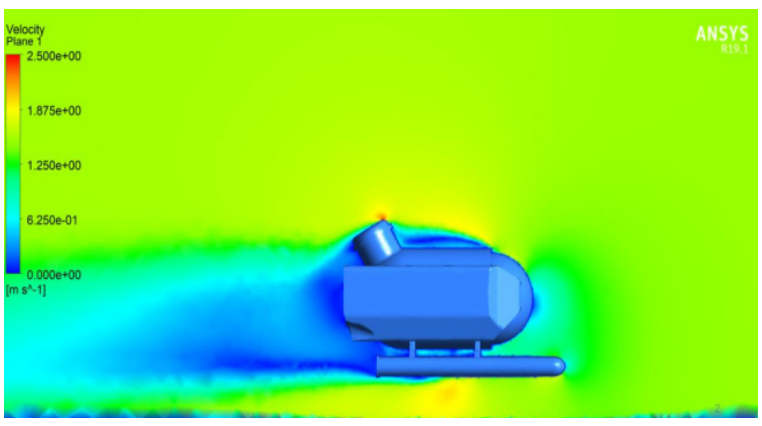

Fig. 11. Velocity distribution in motion near a seabed ( $0.7 \mathrm{~m}$ of bottom, $\left.V_{F}=1.5 \mathrm{~m} / \mathrm{s}, C_{D}=0.442\right)$

The results are given by $k-\varepsilon$ and $k-\omega$ are similar for our case $\left(\operatorname{Re}=1,613 \cdot 10^{7}\right)$. To study the effect of the seabed and free surface we calculate the motion of vehicles very near the water surface $(0.1 \mathrm{~m}$ from free surface) see Fig. 9 and very near seabed $(0.7 \mathrm{~m}$ from the bottom $)$ see Fig. 10 . Simulation of water surface effect, the multiphase model with VOF is used. 
In the case moving on the water surface as ships, the submarine moving on the surface with the base at $1.487 \mathrm{~m}$ deep and the rest outside the water, the simulation requires the presence of two fluids (seawater and air). For this simulation, the VOF (volume of fluid) calculation method and multiphase model are used. Fig. 10 shows the velocity distribution in motion on the water surface.

Table 5. Resistances and coefficients $C_{D}$ in motion forth in infinite fluid $\left(V_{F}=2.5 \mathrm{~m} / \mathrm{s} ; V_{F}=3.0 \mathrm{~m} / \mathrm{s}\right)$

\begin{tabular}{|l|l|r|r|}
\hline Model & $\begin{array}{l}\text { Velocity } \\
(\mathrm{m} / \mathrm{s})\end{array}$ & \multicolumn{1}{|l|}{$V_{F}=2.5$} & \multicolumn{1}{|c|}{$V_{F}=3.0$} \\
\hline \multirow{2}{*}{$k-\varepsilon$} & $F_{D}(N)$ & 7084.8 & 10231.4 \\
\cline { 2 - 4 } & $C_{D}$ & 0.378 & 0.379 \\
\hline \multirow{2}{*}{$k-\omega$} & $F_{D}(N)$ & 7126.5 & 10289.2 \\
\cline { 2 - 4 } & $C_{D}$ & 0.380 & 0.381 \\
\hline \multirow{2}{*}{ Spalart } & $F_{D}(N)$ & 7590.7 & 10766.9 \\
\cline { 2 - 4 } & $C_{D}$ & 0.405 & 0.399 \\
\hline
\end{tabular}

Tables $6,7,8$ show the results of resistance $F_{D}$ and coefficients $C_{D}$ in different motion modes by three viscous models. $k-\omega$ model is best suited for near the wall flow region and small velocity. The value of $C_{D}$ given by the model $k-\varepsilon$ is smaller. The difference between $k-\omega$ and $k-\varepsilon$ is about 0.5 .

Table 6.Resistances $F_{D}$ and coefficients $C_{D}$ in motion back in infinite fluid $\left(V_{B}=1.5 \mathrm{~m} / \mathrm{s}\right)$

\begin{tabular}{|l|c|c|c|}
\hline \multirow{2}{*}{} & \multicolumn{3}{|c|}{ Turbulence model } \\
\cline { 2 - 4 } & $k-\varepsilon$ & $k-\omega$ & Spalart-Allmaras \\
\hline$F_{D}(N)$ & 4027.2 & 4142.9 & 4276.2 \\
\hline$C_{D}$ & 0.597 & 0.614 & 0.634 \\
\hline
\end{tabular}

Table 7. Resistances $F_{D}$ and coefficients $C_{D}$ in motion vertical up $\left(V_{U}=1.5 \mathrm{~m} / \mathrm{s}\right)$

\begin{tabular}{|l|c|c|c|}
\hline \multirow{2}{*}{} & \multicolumn{3}{|c|}{ Turbulence model } \\
\cline { 2 - 4 } & $k-\varepsilon$ & $k-\omega$ & Spalart-Allmaras \\
\hline$F_{D}(N)$ & 8643.5 & 8899.2 & 9259.8 \\
\hline$C_{D}$ & 1.281 & 1.319 & 1.372 \\
\hline
\end{tabular}

Table 8. Resistances $F_{D}$ and coefficients $C_{D}$ in motion vertical down $\left(V_{D}=1.5 \mathrm{~m} / \mathrm{s}\right)$

\begin{tabular}{|l|c|c|c|}
\hline \multirow{2}{*}{} & \multicolumn{3}{|c|}{ Turbulence model } \\
\cline { 2 - 4 } & $k-\varepsilon$ & $k-\omega$ & $\begin{array}{c}\text { Spalart- } \\
\text { Allmaras }\end{array}$ \\
\hline$F_{D}(N)$ & 6096.6 & 6096.5 & 6219.8 \\
\hline$C_{D}$ & 0.903 & 0.903 & 0.922 \\
\hline
\end{tabular}

Table 9 shows the resistances $F_{D}$ and coefficients $C_{D}$ in different motion modes. The effect of the water surface is significant $\left(C_{D}\right.$ increased by $28 \%$ ) and $C_{D}$ increased by $16 \%$ for the effect of a bottom. The resistance coefficient gets very significant in motion vertical up.

Table 9. Resistances $F_{D}$ and coefficients $C_{D}$ in different motion modes and in the same velocity of $1.5 \mathrm{~m} / \mathrm{s}$ )

\begin{tabular}{|l|c|c|}
\hline \multicolumn{1}{|c|}{$\begin{array}{c}\text { Velocity } \\
1.5 \mathrm{~m} / \mathrm{s}\end{array}$} & Resist. $F_{D}(N)$ & $\begin{array}{c}\text { Coefficient } \\
C_{D}\end{array}$ \\
\hline Near seabed & 2982.4 & 0.445 \\
\hline Infinite Fluid & 2587.4 & 0.381 \\
\hline Near free Surf. & 3241.0 & 0.488 \\
\hline Floating & 1760.3 & 0.261 \\
\hline Go up & 8899.2 & 1.319 \\
\hline Go down & 6096.5 & 0.903 \\
\hline
\end{tabular}

Table 10. Velocity in case of greatest thrust (Tumax) in different motion modes. In comparison with real data.

\begin{tabular}{|c|c|c|c|c|}
\hline & $\begin{array}{c}\text { Thrust } \\
\text { Tumax }(\mathrm{N})\end{array}$ & $\begin{array}{c}\text { Coeff. } \\
C_{D}\end{array}$ & $\begin{array}{c}V \text { Calcul. } \\
(\mathrm{Hl} / \mathrm{h})\end{array}$ & $\begin{array}{c}\text { VReal. } \\
(\mathrm{Hl} / \mathrm{h})\end{array}$ \\
\hline $\begin{array}{c}\text { Near } \\
\text { seabed }\end{array}$ & 4512.6 & 0.445 & 4.13 & No date \\
\hline $\begin{array}{c}\text { Forth } \\
\text { infinte } \\
\text { Fluid }\end{array}$ & 4512.6 & 0.381 & 4.44 & $4.2-4.5$ \\
\hline $\begin{array}{c}\text { Back } \\
\text { infinite F. }\end{array}$ & 2589.8 & 0.614 & 2.66 & 2.2 \\
\hline $\begin{array}{c}\text { Near free } \\
\text { Surf. }\end{array}$ & 4512.6 & 0.488 & 3.96 & No date \\
\hline Floating & 4512.6 & 0.261 & 5.37 & No date \\
\hline Go up & 501.2 & 1.319 & 0.025 & 0.1 \\
\hline Go down & 815.6 & 0.903 & 1.33 & 1.2 \\
\hline
\end{tabular}

Table 10 shows the velocity in operation with the greatest thrust. The velocity calculated by $k-\omega$ has a very good correlation with the real data $(0.5-5.0) \%$. Most of the discrepancy between the $C_{D}$ calculated and real data for the case of motion go vertical up $(30 \%)$.

From Fig. 9 and Fig.10, it is seen that when the UVs move near the water surface or when floating, the water surface does not change significantly. This seems different from reality. 


\section{Conclusion}

A RANS simulation with three viscous models for the underwater vehicle motion is proposed. The model $k-\omega$ can be successfully used to calculate the flow around an underwater vehicle moving slowly $\left(R e=1,613 \cdot 10^{7}\right)$. The calculated results also indicate the influence of the bottom and the water surface on the dive vehicle movement. When moving near the bottom, or near the water surface, the ship's resistance increased, thatreduces the speed of the vessel's movement. The simulation results are also indicated for movements with a small velocity $(R e)$ that one can use the $k-\varepsilon$ model or the $k-\omega$ model. These two models produce nearly identical results (approximately $0.05 \%$ ) When it is necessary to calculate the effect of the surface, use the $k-\varepsilon$ model with the VOF method for multiphase (two phases).

The CFD method is shown to be able to provide a good estimate of the resistance of the underwater vehicles with an acceptable level of accuracy. However, more studies are required for more advanced turbulence models, finer grid resolutions, and additional verifications and validations with reality.

\section{Acknowledgments}

The project ĐTĐL.CN-41/18 has supported the implementation of this research work.

\section{References}

[1] D.A. Jone, D.B. Clarke, I.B. Brayshaw, J.L. Barillon, B. Anderson, The Calculation of Hydrodynamic Coefficients for Underwater Vehicles, DSTO COA, July 2002 - Australia

[2] Wilcox, D.C. (1988), Re-assessment of the scaledetermining equation for advanced turbulence models, AIAA Journal, vol. 26, no. 11, pp. 12991310.

https://doi.org/10.2514/3.10041

[3] Martin Renilson, Submarine Hydrodynamics, Springer ISSN2191-530X, 2015.

https://doi.org/10.1007/978-3-319-16184-6

[4] Fossen T. I., Handbook of Marine Craft Hydrodynamics and Motion Control, Wiley 201. https://doi.org/10.1002/9781119994138

[5] Rules for classification. DNV.GL, 2015. https://www.dnvgl.com/maritime/dnvgl-rules.

[6] Le Quang, A study on Stability augmentation for longitudinal modes of a small piston-engine aviation airplane. Tuyển tập công trình khoa học Hội nghị Cơ học Toàn quốc, Tháng 4/2019, Hà Nội. 